\title{
ENTREVISTA REALIZADA COM RICARDO LUCENA -TÉCNICO CAMPEÃO DA LIGA NACIONAL DE FUTSAL
}

\author{
Wilton Carlos de Santana, Universidade Estadual de Londrina, Londrina, Paraná - \\ Brasil
}

Ricardo Lucena foi um dos mais renomados técnicos de futsal do Brasil de todos os tempos. Carioca, nascido em 26/08/54, ex-jogador da modalidade, formado em Educação Física, dirigiu equipes profissionais entre os anos de 1978 e 2008. Nesse tempo, somou diversos títulos estaduais e metropolitanos nos estados do Rio Grande do Sul, São Paulo, Santa Catarina, Pernambuco e Rio de Janeiro. Fez duas finais consecutivas da Liga Futsal, saindo-se vencedor em 2000, quando dirigiu o C. R. Vasco da Gama (RJ), liderando um time de craques, dentre os quais, Manoel Tobias. Com isso, entrou para um seleto grupo de seis técnicos que venceram essa competição, a principal do país, desde 1996. Além da quadra, atuou, por anos, como docente em cursos de extensão e de especialização (lato sensu). Seu livro "Futsal e a iniciação" publicado pela editora Sprint em 1994, se constitui, ainda hoje, em uma referência obrigatória para os leitores da área. Lucena faleceu, precocemente, em meados de dezembro de 2007. Esta entrevista, realizada nessa época, em função do meu doutoramento, expressa parte da sua visão sobre aspectos estratégico-táticos do jogo de futsal.

\section{Lucena, em sua opinião, quais seriam, em linhas gerais, as características mais marcantes do jogo de futsal atual?}

Eu entendo que, dentro do processo evolutivo do desporto, eu falo isso com propriedade porque, talvez, pela minha idade, pelo meu tempo de atuação, a gente possa ter acompanhado todo esse processo, a tendência maior do futsal moderno, hoje, é força e velocidade. O conceitual de técnica fica muito embutido dentro desses fatores condicionantes, quer dizer, a técnica plástica, a técnica artística, que, teoricamente, encanta o público, ela é interpretada, hoje, de uma forma diferente. A gente tem alguns exemplos aí desse jogo plástico, na figura do maior jogador da modernidade, que é o Falcão, que encanta a tantos. Mas no futsal competitivo, a maior competência é quem tem a vontade, quem tem a boa movimentação, quem tem a boa recepção, boa 
finalização e muita condição orgânica para agüentar a puxada de um calendário exaustivo e poder jogar com plenitude. Então acho que esse é o perfil da modernidade.

\section{As características que você mencionou, isto é, a maneira como você percebe o} jogo de futsal como um todo, tem influenciado a sua maneira de treinar a equipe?

Sem dúvida, eu acho que nós temos que estar ali atentos a essa necessidade e ajustar os métodos de treinamento em função das solicitações que a competição te impõe. Senão você vai estar em desacordo com a necessidade premente, que é o ajuste dos valores físicos, técnicos e até mesmo estruturais de jogo, ao que o momento te impõe.

\section{Para qual dos aspectos tradicionais do treino (físico, técnico, tático e psicológico)} você mais tem se dedicado?

Olha, nesses últimos tempos, com a questão da multidisciplinariedade dos recursos humanos, estrutura competitiva, o meu foco tem sido mais para a parte técnica e tática. Então a gente tem distribuído muito essas funções. Eu tenho como linha de atuação fortalecer o componente técnico, que eu acho que é o aporte necessário para a parte estrutural do jogo em relação ao sistema, às manobras, não é verdade? Então eu acho que para você poder ter uma qualidade de jogo efetiva, se faz necessário que você tenha um componente técnico de sustentação, que dê força ao teu jogo coletivo.

\section{Você poderia narrar um tipo de atividade que, habitualmente, aplica para treinar esses aspectos técnico-táticos?}

Bom, teoricamente eu tenho como sustentação a metodologia que eu aprendi com o convívio no basquete. Eu me considero um privilegiado de poder, ao longo da minha existência, já em 1982, ter dividido com o Ari Vidal o espaço de trabalho e, numa ordem de valor, depois com Miguel Ângelo da Luz, depois com Hélio Rubens, depois com a Maria Helena, com a Heleninha. E eu trago muito da metodologia do basquete para o futsal. Isso sempre foi desde o início da minha prática profissional. E eu procuro dimensionar o meu trabalho em relação às solicitações prementes do jogo. O que acontece no jogo? Então a dinâmica do meu trabalho está sempre voltada para quê? As ações de ataque combinando com contra-ataque, combinando com a defesa, combinando com as superioridades e inferioridades numéricas. Então eu não tenho 
aquela cultura do joguinho recreativo para se construir trabalho; joguinho educativo. Eu trabalho dentro da intensidade, da necessidade do jogo. Essa tem sido a minha metodologia e eu tenho ficado satisfeito com ela.

\section{Para um autor português chamado Júlio Garganta, o principal aspecto do treino} em esportes coletivos é, exatamente, a dimensão cognitiva, isto é, a dimensão que traduz a capacidade de o jogador analisar/ler o jogo e tomar decisões inteligentes. Você compartilha dessa idéia?

Não tenha dúvida! Eu acho que para jogar um jogo de alto rendimento, onde a leitura de movimentação faz-se necessária, você não pode botar o atleta só para reproduzir movimento. Ele tem que, em cima dessa reprodução de movimento, ter uma visão crítica, em que ele possa ali estar atento à parte estrutural e, dentro dessa cultura coletiva, ele poder ter autonomia de decidir o momento de passe, o momento de um chute, o momento de uma ação de ataque. Isso tudo é o quê? É a cognição que a gente exercita nessa metodologia. Até porque os meus treinos eles são sempre focados no quê? No raciocínio lógico, no raciocínio do jogo, na posição que o jogo impera. Então eu acho que para minha estrutura de jogo apregoada, o jogador, se não tiver uma cognição elevada, um intelecto aguçado, ele vai ter dificuldade de jogar comigo. Porque o tempo todo eu estou solicitando que ele jogue e pense. Porque eu costumo, eu tenho uma fala que diz o seguinte: "Jogar é fácil, todos jogam. Jogar e pensar, poucos". Daí as diferenças entre as competências.

\section{Lucena: é possível dar liberdade para o jogador num jogo estratégico como o de futsal?}

Sem dúvida! Eu acho que a maior competência de um treinador, de um técnico, é que ele possa colocar à disposição do coletivo a competência técnica de um atleta e que, ao mesmo tempo, esse atleta possa ter autonomia para, em um momento íntimo dele no jogo, ele possa decidir o que fazer. A estratégia, a estrutura de jogo melhor dizendo, a padronização de movimento, ela é um elemento facilitador para que a técnica possa fluir. Eu não quero um jogador gessado. Eu não quero um jogador dependente das minhas intervenções para que ele possa desenvolver as suas potencialidades. Eu quero, sim, que ele possa ser cúmplice meu em um planejamento coletivo de jogo. A minha função é o quê? Operacionalizar todas as competências coletivas, individuais a serviço 
do coletivo. Então eu acho que a maior alquimia do treinador é isso. Ele poder tirar o melhor do jogador, dando-lhe possibilidade de jogar dentro de uma estrutura racional, para que ele possa ter autonomia de decisão.

\section{Você diria que treina sua equipe para obedecer e para criar?}

Não tenha dúvida! Eu acho que nem seria o termo obedecer. Porque o termo obedecer, ele te coloca na condição de submissão. Que eles possam pensar coletivamente como eu penso. Aí eu aponto para a filosofia de jogo, que não seriam nem as jogadas e as manobras. Eu acho que mais difícil para um treinador é ele passar para o jogador a sua forma de ver o jogo, a sua forma de pensar o jogo. E que esses jogadores possam o quê Atuar dentro desse conceitual filosófico. E as manobras elas são exatamente o quê? Reprodução comportamental coletiva, não é verdade? Agora, qual o melhor momento de acioná-la? Qual o melhor momento de criar um ataque? Qual o melhor momento de optar se eu passo, se eu chuto? Isso aí é autonomia do jogador.

\section{Quais qualidades lhe chamam a atenção num jogador de futsal?}

Aí, sem dúvida alguma, eu acho que, acima de tudo, o comprometimento. A maior qualidade de um atleta é ele estar comprometido com a causa. Porque muitas vezes você, no universo da coletividade, você tem os comprometidos e os envolvidos. O comprometido é aquele que abraça a tua idéia, se dedica ao trabalho. Ele, realmente, se doa a todo um processo de preparação em busca de um objetivo o quê? Comum. O envolvido não, ele vai estar ali, vai estar participando desse processo todo e tanto faz para ele ter sucesso ou não. Ele está da mesma forma. Então eu acho que a maior competência, hoje, para que a gente possa diferenciar o "bom do bom" é o comprometimento. Porque na medida em que ele está comprometido, ele vai se dedicar a todo o processo de preparação e, uma vez se dedicando a esse processo de preparação, consequentemente, a gente vai poder observar o quê? A evolução dele dentro dessa linha, dessa filosofia de trabalho.

\section{Do ponto de vista tático, quais qualidades lhe chamam atenção num jogador?}

Bom, aí é uma questão de interpretar a tática. Dentro da minha leitura, eu tenho a abrangência da tática em que ela te dá três níveis: estrutural, tática de competição e a tática específica. A estrutura envolve o quê? Toda a infra-estrutura na qual eu vou 
desenvolver o meu planejamento, meu projeto. A de competição está ligada ao quê? Ao calendário em que eu vou atuar durante uma temporada. Então, muitas vezes, a equipe de ponta é extremamente sobrecarregada com mini-competições, principalmente se é uma equipe de investimento. E a tática específica envolve o quê? As nuances do jogo. Então, no que diz respeito às nuances do jogo, envolvendo o quê? Sistemas, manobras, as estratégias específicas para uma partida; as estratégias específicas para um momento do jogo. Esse, realmente, é um grande diferencial! Você estar preparado para essas questões.

10. Sabe-se que o jogador de futsal atua, hoje, a maior parte do tempo sem a bola. Isso, de alguma forma, influencia a sua maneira de treinar a equipe?

Não tenha dúvida! Até porque eu acho que no jogo de futsal, em função do grande desempenho físico com o advento da modernidade, os recursos ergogênicos, os meios de preparação, a competência cada vez mais da figura dos preparadores físicos, dão um condicionamento orgânico absurdo a esses jogadores. A ciência disponível a essa linha de preparação. Então, consequentemente, o espaço ficou pequeno. Então, para a posse de bola ter eficiência é muito mais importante o apoio à posse do que propriamente a posse. Então, eu acho que quem joga sem bola, hoje, anda muito mais do que quem anda com a bola. Porque quem anda sem a bola, quem joga sem a bola, tem que estar sempre o quê? Na posição de servir, de apoiar. Então, é muito importante essa consciência de quem faz apoio ao passe, de estar sempre disponibilizando o quê? A sua aproximação para servir a quem tem a posse. E com isso evitar o quê? O contato direto das linhas de defesa.

\section{No futsal de hoje, quem mais tem chance de sucesso: o jogador especialista ou o versátil?}

Seria o generalista; o generalista. Teoricamente, a tendência do jogo é você, cada vez mais, necessitar das posições de base. Na medida em que você cria um generalista, ele consegue executar bem uma função de pivô, executar bem uma função de ala, executar bem uma função de fixo... Porque, teoricamente, dentro dessas posições de base - eu qualifico como posições de base - nós podemos ter, lá, várias nuances. Eu posso ter um fixo de antecipação; eu posso ter um fixo de apoio; eu posso ter um fixo de marcação; eu posso ter um ala de armação; eu posso ter um ala de aproximação; eu posso ter uma 
ala de finalização; eu posso ter um pivô de referência; um pivô de distribuição; um pivô de definição. Então, é importante que esse atleta possa ter, pelo menos, três competências diferenciadas. Isso é um pouco difícil! Um cara que reúna todas essas competências, por todas essas posições. Essa é a grande verdade. Agora, na medida em que você trabalha de forma coletiva, eu procuro, na minha dinâmica, não me ater muito a essa posição "O beque é beque, o ala é ala...”. Eu facilito o quê? Que todos possam experimentar diferentes posições e, dentro desse experimento, tentar chegar o mais próximo possível dessas competências de ser finalizador, de ser de aproximação, de ser defensivo. Então, essa é a leitura do generalista. Embora isso requeira o quê? Um tempo de exercício. Porque, tecnicamente, todos são competentes. A questão é só de ajustar aonde? Aos referenciais de espaço. 